\title{
O MEDO EM HISTÓRIAS ASSUSTADORAS PARA CONTAR NO ESCURO
}

Felipe Ribeiro Campos (UERJ)

Resumo: Histórias Assustadoras para Contar no Escuro é o primeiro livro de uma trilogia de sucesso que busca compilar diversos contos de medo existentes no folclore norte-americano. Para causar o efeito esperado no leitor, os contos usam elementos conhecidos do gênero: espíritos vingativos, cenários amaldiçoados, figuras com poderes sobrenaturais, situações corriqueiras que se transformam em verdadeiros pesadelos, atos e consequências piores que a morte. $O$ livro transita entre diversas formas de utilizar o horror na narrativa, por vezes criando atmosfera de tensão e insegurança para o momento final, mas também utilizando o artifício do susto com informações - ou atitudes do narrador inesperadas. Como embasamento teórico para a pesquisa, nomes como Rosalba Campra, David Roas e Julio França, autores que pensam a literatura fantástica.

Palavras-chave: Medo; Contos; Juvenil; Horror.

Abstract: Scary Stories to Tell in the Dark is the first book of a successful trilogy that intends to compile several horror tales in American folklore. To cause the expected effect on the reader, the stories use elements known to the genre: vengeful spirits, cursed landscapes, characters with supernatural powers, common situations that turn into real nightmares, acts and consequences worse than death. The book moves between different ways of using horror in the narrative, sometimes creating an atmosphere of tension and insecurity for the final act, but also using the artifice of fright with unexpected information (or narrator's attitudes). As a theoretical basis for the research, names like Rosalba Campra, David Roas and Julio França, authors who think about fantastic literature.

Keywords: Fear; Tales; Young Readers; Horror.

Alvin Schwartz é um autor que tem o trabalho de recolha e reconto de diversas histórias do folclore americano e, especificamente em Histórias Assustadoras para Contar no 
Escuro, publicado em 2016 no Brasil e primeiro livro de uma trilogia bem-sucedida, foca em contos de medo. No texto de apresentação, intitulado "Coisas estranhas e assustadoras", ele explica um pouco sobre o hábito que a humanidade tem de reunir pessoas e compartilhar histórias de terror desde antigamente. Por ser um livro voltado para o público juvenil, o autor acha interessante dizer o porquê de o gênero fazer tanto sucesso:

Contar histórias assustadoras é algo que as pessoas vêm fazendo há milhares de anos, porque a maioria de nós gosta de sentir esse tipo de medo. Como as emoções são fruto da imaginação, e ninguém corre perigo de verdade, achamos que é divertido. (SCHWARTZ, 2018, p.9)

Outro ponto que o autor chama a atenção é a forma como a história pode ser apresentada. A primeira parte do livro é dedicada a contos que dão instruções entre parênteses para os contadores e o resultado é interessante e diferente: "(Ao dizer a última frase, agarre o braço de um de seus amigos)" (2018, p.17), "(Agora DÊ UM GRITO!)" (2018, p.19) e "(Ao pronunciar as últimas palavras, bata o pé no chão com força e pule na direção de um ouvinte próximo a você.)" (2018, p.22) são bons exemplos de como a obra interage com seus leitores. 
A fim de entender melhor o fio condutor presente em todos os contos, mesmo que em maior ou menor escala, é interessante observarmos certos pesquisadores e conceitos com os quais, ao nos debruçarmos sobre as narrativas, identificaremos as ferramentas utilizadas para causar determinadas reações nos leitores. David Roas aponta em um de seus artigos que o medo é o "efeito básico do fantástico" (2011, p.46) e o livro se beneficia dessa emoção. Sobre o efeito real do medo, Adrian Furnham afirma que o medo impera em muitas situações humanas (ser atacado durante à noite, por exemplo), acionando um conjunto de circunstâncias ou rotinas:

Para começar, você fica atento a determinados estímulos visuais ou auditivos. Depois, as suas prioridades e objetivos mudam: fome, dor e sede são suprimidos para garantir a segurança. Em terceiro lugar, os sistemas de coleta de informações se concentram em questões específicas. Em quarto lugar, alguns conceitos simples surgem ou mudam de fácil e difícil para perigoso ou seguro. Em quinto lugar, são acionadas memórias de eventos passados similares à presente situação. Em sexto lugar, pode haver uma tentativa de se comunicar, de maneira bastante incomum, por meio de gritos ou choro, ou até o contrário, quando a pessoa se vê paralisada pelo medo e incapaz de emitir qualquer som. Em sétimo lugar, um sistema de inferências ou teste de 
hipóteses é acionado para a pessoa tentar entender o que está acontecendo e o que deve acontecer em seguida. Em oitavo lugar, sistemas de aprendizagem são ativados e, em nono lugar, sistemas fisiológicos são acionados. Esses sistemas podem resultar em uma reação de lutar ou fugir que, por sua vez, leva a uma série de regras de decisões comportamentais. Desse modo, a pessoa pode fugir correndo ou até atacar. (2016, p.64)

Os contos se apropriam de medos comuns e os utilizam como elementos nas narrativas, dentre eles, o de ser seguido por algum desconhecido: "O sonho de perseguição também é bastante comum: normalmente o sonhador é implacavelmente perseguido ou talvez esteja perseguindo as pessoas" (FURNHAM, 2016, p.145). O efeito do medo em arte, mesmo que não cause mal diretamente ao leitor, é vivido por ele e é por isso que sente aflição, desconforto, tensão, desespero, alívio ou susto. Para que a catarse aconteça, o medo e o fantástico precisam estar próximos:

Segundo a perspectiva de Alain ChareyreMejan (1990), o efeito de medo presente no fantástico não é provocado pelo modo de ver as coisas, mas sim pela constatação daquilo que acontece em si ou daquilo que está "insuportavelmente posto aí", diante de alguém, independente de uma certa maneira de ver. Assim, as coisas são desagradáveis ao olhar não pela sua carga de representação 
repulsiva, mas sim pela "neutralização de todas as significações em geral.

(BATALHA, 2012, p.491)

De todos os medos, o da morte é considerado o mais intenso:

O mistério da morte - seu caráter tão inexorável quanto insondável - é a mola mestra de narrativas que tematizam essa região da experiência humana sobre o qual a ciência, o discurso da verdade demonstrada, pouco tem a dizer. Nos desvãos entre a fé religiosa e o conhecimento científico, as obras ficcionais que lidam com o medo encontram seu hábitat ideal. O terror atávico em relação ao nosso derradeiro destino é a própria garantia da atração e da universalidade do medo. (GARCÍA; FRANÇA; PINTO, 2013, p.9)

Faz-se necessária uma rápida apresentação dos contos separados por capítulos - da mesma forma que se encontram no livro - para que, mais adiante, fique clara a relação entre sobrenatural, medo, atmosfera sinistra e cenários em histórias de susto para, assim, dar início à discussão sobre o fantástico e à utilização de elementos grotescos dentro da obra.

O primeiro capítulo tem por título "Aaaaaaaah!", acompanhada da informação de que as histórias objetivam fazer os leitores e ouvintes pularem da cadeira. São contos organizados deliberadamente com a intenção de assustar. No primeiro deles, "O dedão do pé" existe a relação de causa 
e consequência quando um dedão gigante é encontrado no jardim da casa por um menino e toda a família o come em um ato de canibalismo. Posteriormente, a casa é invadida por algo que pede o dedão de volta, com uma voz a princípio longe e cada vez mais próxima, até chegar ao quarto da criança, criando um clima de tensão. Em "A caminhada", existe o encontro da personagem principal, tio do narrador, com um estranho/desconhecido que caminham lado a lado, aumentando o pavor dos dois. Em "Por que você está aqui?", a máxima do "cuidado com o que você deseja" aparece na história de uma senhora solitária que quer companhia durante a noite, mas o que aparece é um cadáver querendo buscá-la, o que desestrutura a casa como lugar sinônimo de proteção.

No conto "Estou amarrada, corajoso andarilho!", a imagem grotesca de uma cabeça ensanguentada que cai da chaminé todas as noites é o mote para uma aposta cuja regra é alguém conseguir passar uma noite nessa casa assombrada, um lugar considerado amaldiçoado. Quando um menino e seu cachorro decidem enfrentar o desconhecido, ouvem a voz que se aproxima até o aparecimento da cabeça. O poema "Um homem que morava em Correntes" não tem muito sentido e suas imagens causam estranheza e incômodo, mas a partir da menção a um leão e sua presa e depois a uma faca 
no peito do narrador, o texto torna-se violento e angustiante. O conto "Uma velha só pele e osso" se utiliza das figuras da velha mulher e, mais tarde, de um cadáver, para causar medo ao leitor e levar à reflexão sobre a proximidade da morte.

A segunda parte intitula-se "Ele ouviu passos subindo as escadas do porão..." e agrupa narrativas de fantasmas, envolvendo acontecimentos estranhos e misteriosos. Em "A coisa", uma criatura de olhos "fundos na cavidade ocular, embora vivos e penetrantes" (2018, p.33) aparece para dois garotos e, num jogo de se esconder e se revelar, ela vai em direção aos amigos, que também se aproximam, tentando descobrir se o ser é verdadeiro ou não. Eles fogem, seguidos pelo esqueleto, que parece representar uma espécie de "precursor da morte", a imagem decrépita, futura, de como a personagem será quando morrer, como ocorreu com um dos meninos, um ano depois da aparição. "Frio como o barro" é mais um conto que lida com o que acontece depois da morte quando a pessoa não consegue descansar, configurando um outro estado de existência que não o fim, quando a personagem não aceita ou não reconhece que está morto e interfere no mundo empírico dos vivos.

Em "O lobo branco" vemos a inversão de papéis de caça e caçador e a força da natureza com ares sobrenaturais e 
extraordinários na figura de um lobo sobrenatural, que surge causando diversas mortes de outros animais e, por fim, do homem que tenta abatê-lo. O conto "A casa mal-assombrada" apresenta, como protagonista, um padre que se propõe a levar paz a um fantasma que assombrava o local há muito tempo. O religioso enfrenta o fantasma, perguntando-lhe quem é e o que deseja, e descobre que o fantasma precisa de ajuda para resolver algo que ficou pendente no plano ficcional dos vivos. "Os convidados" é mais um caso no qual tudo parece estar dentro da normalidade, mas todo o cenário e suas personagens são da área do sobrenatural: um casal está viajando e decide parar durante a noite, o único lugar próximo é uma casa onde mora um casal de idosos que, mais tarde, é sabido que estavam mortos.

Próxima seção, a terceira, tem por título "Eles devoram seus olhos, eles devoram seu nariz" e, por tema, histórias assustadoras focalizando diversos elementos. "A canção do carro fúnebre" é sobre a morte, o medo que ela causa e sobre o que acontece depois, utilizando mais uma vez a imagem do cadáver sendo devorado por larvas a fim de causar nojo no leitor. No conto "A garota que ficou de pé sobre uma sepultura", há um cemitério "silencioso como a morte" (2018, p.51) como cenário, e parece que algo no âmbito do 
sobrenatural acontecerá: uma menina aceita uma aposta de ficar de pé sobre uma sepultura, como sugere o título, e fincar um canivete no chão, como prova de que realizara o feito. Em "Um novo cavalo", a fazenda é o cenário onde um agricultor é enfeitiçado por uma bruxa que o transforma em cavalo para que cavalgue pelos campos. Em "Jacarés", a natureza mais uma vez é terreno para o insólito e, nesse caso, para a hesitação, já que o leitor não tem a certeza de que os jacarés seriam na verdade o marido e os filhos da mulher, pois no final do conto ela é dada como louca.

Talvez um dos mais assustadores contos do livro, "Tem espaço para mais um" conta a história de um homem de viagem a negócios que, ao dormir na casa de amigos, vê a certa hora da madrugada, através da janela de seu quarto, um carro fúnebre na rua, cujo motorista tem um rosto medonho, que o assusta. A situação, porém, ao ser relatada aos amigos, é interpretada como pesadelo. No dia subsequente, porém, o pesadelo torna-se uma premonição - ou coincidência macabra - quando o protagonista, em um arranha-céu da cidade, vê o motorista do carro no elevador, que despenca, caindo no poço e matando as pessoas que dentro dele se encontram.

"A Wendigo" traz um espírito da floresta como figura vilanesca em uma área proibida onde dois homens insistem 
em caçar, mostrando assim a moral da maldição e do castigo pela desobediência, além de um destino pior do que a morte. "Os miolos do morto" é uma narrativa que está mais para um jogo/teste de coragem do que para um conto: os participantes são desafiados a colocar a mão em potes cobertos com pano e sentir o que está lá dentro, enquanto o narrador diz que os conteúdos são partes do corpo de um homem assassinado. Em "Posso carregar o seu cesto?", a ação acontece por volta de meia-noite, "na rua fazia um frio congelante e estava tão silencioso quanto um cemitério" (2018, p.68). O protagonista voltava para casa, quando, no caminho, aparece uma assombração que perturba o narrador e, como o conto se passa em um local corriqueiro, deixa a sensação de que pode acontecer com qualquer um.

A quarta seção, "Outros perigos", reúne, segundo o autor, histórias, mais recentes sobre aspectos ligados ao cotidiano, contadas por jovens. "O gancho" é a conhecida lenda urbana do casal que está namorando no carro estacionado próximo a uma prisão, de onde fugiu um homem com uma faca e um gancho no lugar de uma das mãos. Quando decidem finalmente voltar para casa, graças ao medo da jovem, o rapaz vai abrir a porta para que ela saia, e vê o gancho preso na maçaneta. “O vestido branco de cetim" também não traz 
o sobrenatural como elemento para o medo, mas apresenta a morte como resultado para o acontecimento principal da história: a narrativa conta a história de uma jovem que aluga um vestido para um baile, no qual se diverte muito, mas é encontrada morta na cama, na manhã seguinte, pela mãe. Em "Faróis altos", o medo se instala com a tensão criada na narrativa: uma moça volta para casa, à noite, quando percebe que está sendo seguida por um outro carro. Ela tenta escapar de todas as maneiras, tanto acelerando o carro quanto enveredando por um caminho pouco usual, mas o motorista a segue, por vezes acendendo os faróis altos, o que a deixa temporariamente cega. Ao chegar à casa e pedir ao pai para chamar a polícia, o mistério se desfaz: o perseguidor foi quem salvou a protagonista de um assassino que tinha entrado em seu carro e estava escondido no banco de trás com uma faca.

"A babá" também é uma lenda urbana popular, sobre uma jovem que cuida de três crianças e que, durante uma noite, recebe constantemente telefonemas anônimos de uma pessoa dizendo que está cada vez mais próxima, ameaçando-a, até que é revelado que os telefonemas estão sendo feitos do segundo andar da casa, ou seja, o maníaco já tinha invadido o local e estava prestes a atacar quando 
a jovem consegue fugir com as três crianças. Os contos dessa seção são diferentes dos demais, pois não têm o insólito como parte da história, mas mantêm cenários que são próximos aos leitores, o que facilita a imersão. Como o autor adverte, "São histórias que os jovens costumam contar sobre os perigos que enfrentamos no dia a dia" (2018, p.71).

A quinta e última seção de contos traz o mesmo título da primeira - "Aaaaaaaah!" -, mas enquanto as primeiras histórias têm a intenção de assustar, as últimas pretendem provocar o riso no leitor. Talvez possamos entender a expressão do título como pertinente as duas situações interlocutivas, ou ainda pensar que susto e riso caminham muito próximos. Em "A dor anunciada" existe a quebra de expectativa com efeito cômico, quando conhecemos uma senhora que não ouve direito os telefonemas que recebe e acha que está sendo ameaçada. O desaparecimento do cachorro de um caçador é a história do conto "O sótão", que tem seu maior momento de nervosismo quando o homem sobe a escada para investigar barulhos estranhos vindos da parte da casa. O breve poema "O temível monstro marinho" não tem fôlego para criar a atmosfera necessária para assustar, mas é um acerto como terrir (combinação entre terror e comédia) ao configurar o mar como cenário e um monstro que ataca todos os companheiros do narrador. 
"Os ossos de Aaron Kelly" apresenta um homem que morreu, mas que se recusa a admitir a sua condição de morto, pois se sente vivo. Ao voltar para casa, ele não assusta as personagens que, na verdade, ficam incomodadas com aquela presença desagradável e indesejada, até descobrirem que, ao ouvir música, o esqueleto se desmonta. A narrativa mostra uma cena bem grotesca, causando mais estranheza e asco, com um pouco de riso, do que medo propriamente dito. O conto "Vamos esperar até Martin chegar" é mais um caso de casa mal-assombrada, aqui por três gatos pretos, um maior que o outro. Os animais aparecem para um homem que invade o local para se proteger de um forte temporal. A última narrativa, "O fantasma com dedos ensanguentados", se passa em um hotel com um quarto assombrado e, mesmo com o aviso do recepcionista, algumas pessoas insistem em passar a noite lá por não haver outra acomodação disponível. O alívio cômico acontece quando um dos hóspedes consegue propor uma solução para o fantasma.

Depois do contato com todas estas narrativas curtas, podemos pensar na classificação da romancista e poetisa Ann Radcliffe acerca das nuances e dos objetivos da literatura de medo: "terror e horror são completamente opostos: aquele expande a alma e desperta as faculdades a um alto grau 
de vida; este contrai, congela e quase as aniquila" (2018, p.82). Com base nisso, há o estado de alerta enquanto não sabemos o verdadeiro perigo que a personagem corre: nossa imaginação trabalha diversas possibilidades para uma silhueta, um som ou movimento e, por outro lado, por conta do medo, muitos ficam paralisados quando estão de frente com aquilo que os ameaça, seja monstro ou fantasma. Interessante perceber que de qualquer forma é a sensação de insegurança e de perigo próximo que conduz as narrativas, mesmo as que têm uma piada no fim, mostrando que existem diversos caminhos para causar desconforto no leitor.

Uma das formas de deixar o leitor apreensivo é criar ritmo na história, em que elementos apareçam de maneira crescente, adicionando tensão até que a situação finalmente surja para, na maioria das vezes, não ter escapatória. Quando uma senhora, por exemplo, fala sozinha desejando companhia à noite e partes de um corpo caem aos poucos da chaminé até montar um cadáver completo, a expectativa do que vai acontecer no conto "Por que você está aqui?" chega ao clímax quando o morto fala "Estou aqui para pegar VOCÊ!" (2018, p.22) e todo esse jogo é tão envolvente, o clima tão bem estruturado ao longo do texto que não há espaço para dúvida se aquilo está realmente acontecendo. 
O final impactante com uma informação totalmente inesperada também provoca surpresa e, por vezes, medo. Todavia, a diferença com relação ao modo de escrever apresentando aos poucos os elementos sobrenaturais é que, em um único golpe rápido, para pegar o leitor despreparado, a história toma um rumo completamente diferente. Relendo o conto, porém, pistas são encontradas ao longo da narrativa, pois é com uma nova perspectiva que o leitor retorna ao texto que, vendo de outra forma, fazem sentido.

Há um texto de Schwartz após os contos em que ele comenta sobre as diferentes versões de histórias que deram origem a outras. Como muitos contos que estão no livro focalizam mortos, figuras cadavéricas ou fantasmas, cabe uma explicação do que motiva o fascínio por esses seres.

Em quase todas as civilizações, existe a crença de que os mortos voltam por diversos motivos. Ou porque suas vidas chegaram ao fim antes da hora. Ou porque não foram sepultados de maneira adequada. Ou porque tinham algum assunto importante a resolver ou alguma missão que precisava ser cumprida. Ou porque queriam punir alguém ou se vingar. Ou porque desejavam trazer conforto a alguma pessoa ou dar um conselho, ou, até obter o perdão de alguém. (2018, p.104-105) 
Outra lenda bastante difundida mencionada pelo autor é a da mochileira que pede carona nas estradas ${ }^{1}$. Existem algumas versões brasileiras, mas uma das mais estudadas é a que está em um cordel de J. Borges, intitulado "A moça que dançou depois de morta"2 . O cordel narra a história de uma jovem que conhece um rapaz no baile e, depois de alguns beijos, o rapaz dá carona para a moça até a casa dos pais dela. No dia seguinte, ainda apaixonado, o rapaz vai até a casa da moça para reencontrá-la, mas descobre pela mãe dela que a filha estava morta.

Importante pontuar que na maioria dos contos do livro, com exceção do capítulo voltado para as lendas urbanas, o sobrenatural é o que desestabiliza o leitor:

Em efeito, quando se aprofundam as motivações que levam a definir um texto como fantástico ou realista, muitas vezes fica evidente que os parâmetros segundo os quais se estabelece a definição do real costumam reduzir-se a uma definição pessoal do leitor. Quando o real representado coincide (ou pode coincidir) com a experiência, o problema da "realidade" do texto não costuma despertar o interesse dos críticos, como

1 Uma versão é que uma mulher de branco pede carona aos carros que passam e, em determinado trecho da estrada, ela diz que teria sido ali o acidente que Ihe tirara a vida: "Estão vendo aquela curva? Foi ali que eu morri", fazendo com que as pessoas encontrem o mesmo destino que o dela. In http://www.lendarium.org/narrative/lenda-da-mulher-debranco/?tag=2925 Acesso em 22Jul.2019.

2 Transformada em um curta em animação em 2003, a obra participou de festivais e ganhou vários prêmios. In http://portacurtas.org.br/filme/?name=a_moca_que_dancou_depois_de_ morta Acesso em 22Jul.2019. 
acontece com o acúmulo de coincidências, desencontros e reconhecimentos dos romances de capa e espada: são aventuras extraordinárias, até altamente improváveis, mas consideradas de todos os modos como possíveis. Quando, em contrapartida, o real representado não coincide em algum aspecto, ou em todos eles, com a experiência da realidade extratextual, como acontece com os vampiros, o tempo circular ou a materialização dos sonhos, o problema da "realidade" do texto se considera em termos de mitologia, lenda, fábula, etc. - gêneros em que se aceita a superposição de diferentes modos de realidade -, ou, drasticamente, relegam os fatos à esfera da alucinação: são o impossível. (CAMPRA, 2016, p.31)

A ilustração de capa do livro não deixa dúvidas de que se trata de um livro de medo/terror/horror: o ilustrador Brett Helquist, que também é responsável pelas ilustrações em preto e branco do miolo, apresenta uma capa com predominância das cores ocre e marrom, tons terrosos que fazem referência à podridão, à ferrugem, ao envelhecimento e à decomposição. O céu, por sua vez, exibe uma cor completamente diferente do que seria a calmaria do azul e passa a sensação de névoa ameaçadora, pesada e malcheirosa. O verde, que também pode remeter à ideia de mofo ou de estragado, com o ocre em sua composição, traz profundidade ao céu sem estrelas quando está mais azulado e, mais claro, colore o capim que parece ser balançado pelo vento. 
Em primeiro plano, vemos uma lápide com o título do livro, os nomes dos autores e um canivete encravado na terra com um pano branco manchado de sangue. O sangue como detalhe macabro que faz referência direta a um dos contos, assim como a figura fantasmagórica ao fundo. Outras referências encontradas e que ajudam a construir a atmosfera sinistra são: o cemitério com lápides tortas de diferentes formas e tamanhos em sua arquitetura característica; as árvores secas com galhos, que lembram dedos compridos e ossudos, e troncos com diversas protuberâncias; os corvos (um deles pousado na lápide observando o que está escrito) e a lua cheia. As ilustrações junto aos contos podem ser de página inteira ou apenas vinhetas, e são mais bem-humoradas do que assustadoras, por não carregarem o peso que a atmosfera sinistra de histórias de horror precisa ter, então, muitas vezes o texto é mais assustador que as imagens.

Não há como pesquisar sobre a atmosfera de medo que situa o leitor sem pensar na literatura gótica e seu romance pioneiro $O$ castelo de Otranto, escrito em 1764 por Horace Walpole. Segundo o escritor, o que muitas vezes chamamos de "contrato" ou acordo entre autor e leitor deve existir para que a história convença, dentro de seu próprio universo. $\mathrm{O}$ interlocutor, é apoiado nessas regras, e, assim, quem está 
lendo, a partir do momento que começou a narrativa até finalizar, teoricamente vai acreditar em tudo que estiver escrito. As estratégias, no entanto, precisam estar bem construídas (e podem não estar) ou, mesmo assim, o leitor cético pode desconfiar ou desdenhar da história:

Se se admite essa atmosfera miraculosa, o leitor não encontrará mais nada indigno de sua leitura. Admita-se a possibilidade dos fatos e todos os personagens comportarse-ão como pessoas reais se comportariam em tal situação. Não há grandiloquência, símiles, floreios, digressões ou descrições desnecessárias. Tudo leva diretamente à catástrofe. A atenção do leitor nunca relaxa. (WALPOLE Apud FRANÇA; ARAÚJO, 2018, p.66)

Quanto à ambientação em histórias para crianças e jovens, tanto por parte da ilustração quanto do texto, a relação entre as duas linguagens - a verbal e a não verbal é importante, uma depende da outra, não necessariamente como complemento, mas também seguindo caminhos opostos. O estilo de desenho igualmente deve combinar com o tom da narrativa e acompanhar o tipo de texto (normalmente, na confecção de um livro, a parte escrita é finalizada primeiro para que as ilustrações comecem a ser produzidas). As ilustrações precisam acompanhar o texto verbal e transformar em imagens a atmosfera criada por 
meio das palavras. Podemos analisar o seguinte pensamento sobre a importância da ilustração:

A ambientação de um livro ilustrado estabelece a situação e a natureza do mundo onde ocorrem os eventos da história. Ao grau mais simples, ela comunica um sentido de tempo e lugar para as ações retratadas, mas pode ir muito além disso: de acordo com as expectativas que definem o gênero (conto de fadas, fantasia); na construção de um clima afetivo geral que influencia em como o leitor reage emocionalmente a determinado episódio (grotesco, nostálgico, cotidiano); no incentivo ao desenvolvimento do enredo por meio do contraste ou mudança drástica nas situações (em casa/ distante de casa, cidade/ campo, guerra ou outro desastre); e no comentário sobre o personagem. Os livros ilustrados incorporam essas funções da ambientação sem limites [...]. (NIKOLAJEVA; SCOTT, 2011, p.85)

Se nos debruçarmos apenas na literatura de medo, podemos voltar ao "contrato" de Walpole e à estrutura que o gênero carrega, pois o senso comum conduzirá imagens de lugares sombrios, claustrofóbicos, assustadores, silenciosos e distantes e, preferencialmente, durante a noite. Ainda tratando de ambientação, o que o livro faz, muito bem, é mostrar a proposta no começo de cada capítulo. No início de cada conto, há o detalhamento do espaço, às vezes aproveitando algum cenário conhecido do público como 
amedrontador ou fazendo funcionar a imaginação de como seria um lugar propício para uma história com o objetivo de causar medo.

Parecida com a caracterização, a ambientação demonstra muito bem a diferença entre diegese (contar) e mimese (mostrar). Enquanto as palavras podem apenas descrever o espaço, as imagens podem efetivamente mostrá-lo, fazendo isso de modo muito mais eficaz e, em geral, mais eficiente. Na teoria narrativa, a descrição é um dos sinais da presença do narrador no texto. O narrador verbal força o leitor a "ver" certos detalhes do cenário, ao mesmo tempo que ignora outros. A representação visual do cenário é "inenarrada" e, por isso, não manipuladora, dando ao leitor considerável liberdade de interpretação.

(NIKOLAJEVA; SCOTT, 2011, p.85)

Discordando um pouco da citação acima, considera-se que quando o ilustrador escolhe o que estará em primeiro plano ou a qual elemento da cena ele dará mais destaque, há, em certo sentido, a manipulação da atenção de quem vê. Também teórica no assunto, Nelly Novaes Coelho dedicou algumas páginas de seu livro Literatura infantil: teoria, análise, didática para abordar os conceitos de espaço e atmosfera:

O ponto de apoio para a ação das personagens é o espaço (ambiente, cenário, cena, mundo exterior). Ele determina as circunstâncias 
locais, espaciais ou concretas, que dão realidade e verossimilhança aos sucessos narrados. Sua importância na efabulação é idêntica àquela que o mundo real adquire em nossa vida cotidiana. (2000, p.77)

Discorrendo ainda sobre as funções do espaço em que uma delas seria a de criar uma atmosfera apropriada para que os conflitos da história possam acontecer, reforçando os argumentos apresentados anteriormente:

Por exemplo, nas histórias de terror, os castelos mal-assombrados; noites escuras; noites de tempestades; casas abandonadas; portas que se abrem sozinhas; etc. Ou ainda a funcionalidade do espaço na ficção científica, nas narrativas que se desenrolam além $d a$ imaginação... [...] A atmosfera criada pelo espaço pode transmitir sensações de calor, frio, luminosidade, escuridão, opressão, transparência, bem-estar, fatalidade, leveza, colorido, opacidade, etc.

(COELHO, 2000, p.78)

A opção por ilustrações em preto e branco afasta a obra do conceito de livro infantil, geralmente colorido, e lhe confere um ar mais sério, mesmo que o estilo de desenho não o seja. O trabalho com tons de cinza se mostra mais adequado ao livro. Ressaltam-se também duas exceções com relação ao planejamento das ilustrações quanto ao texto: O conto "Tem espaço para mais um" coloca a ilustração de vinheta como uma informação acima do título, a princípio fora de 
contexto, mas resgatada ao término do conto. A imagem de página inteira encontra-se no meio da narrativa, a fim de obter maior impacto pelo fato de não ficar tão dissociada do trecho que se propõe representar. Já "O temível monstro marinho" é o único caso de interação perfeita entre texto e ilustração no livro: na parte em que o protagonista é atacado pelo monstro gigante, o texto é atravessado por um de seus tentáculos, mostrando que a personagem foi atacada e devorada - para isso, o tentáculo abraça um dos versos e faz o movimento de captura da palavra, revelando o destino trágico do narrador.

Histórias assustadoras para contar no escuro é um livro que utiliza constantemente o elemento fantástico para causar medo em seus leitores de diferentes maneiras. Ele também se dedica a tentar entender o porquê de gostarmos tanto de histórias de terror, por meio da pesquisa e das palavras do próprio autor, nos textos que abrem e encerram a obra.

\section{REFERÊNCIAS}

BATALHA, Maria Cristina (2012). "Literatura fantástica: algumas considerações teóricas". Letras \& letras: revista do Instituto de Letras e Linguística, 28(2), Uberlândia.

CAMPRA, Rosalba (2016). Territórios da fiçcão fantástica. Rio de Janeiro: Dialogarts.

COELHO, Nelly Novaes (2000). Literatura infantil: teoria, análise, didática. 7.ed. São Paulo: Moderna. 
FRANÇA, Júlio; ARAÚJO, Ana Paula (Orgs.) (2018). As artes do mal: textos seminais. Rio de Janeiro: Bonecker Acadêmico.

FURNHAM, Adrian (2016). 50 ideias de psicologia que você precisa conhecer. São Paulo: Planeta.

GARCÍA, Flavio; FRANÇA, Júlio; PINTO, Marcello de Oliveira (Orgs.) (2013). As arquiteturas do medo e o insólito ficcional. Rio de Janeiro: Caetés.

NIKOLAJEVA, Maria; SCOTT, Carole (2011). Livro ilustrado: palavras e imagens. São Paulo: Cosac Naify.

RADCLIFFE, Ann (2018). "Do sobrenatural na literatura". In: FRANÇA, Júlio; ARAÚJO, Ana Paula (Orgs.). As artes do mal: textos seminais. Rio de Janeiro: Bonecker Acadêmico.

ROAS, David (2011). Tras los limites de lo real: una definición de lo fantástico. Madri: Páginas de Espuma.

SCHWARTZ, Alvin (2018). Histórias assustadoras para contar no escuro. Rio de Janeiro: José Olympio.

Felipe Ribeiro Campos é Graduado em Gravura (UFRJ) e especialista em Literatura infantil e juvenil (UFRJ). Grupo de Pesquisa A narrativa ficcional para crianças e jovens: teorias e práticas.

E-mail: felipe.frcampos@gmail.com

ORCID ID: https://orcid.org/0000-0002-2101-7309 